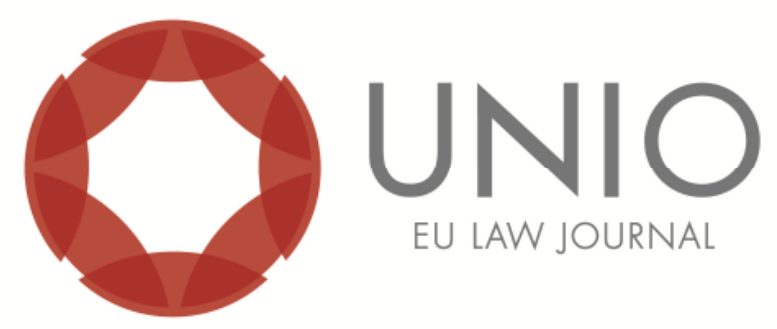

\title{
United Europe and Euclidean Pluralism On the Anthropological Paradox of Contemporary EU Legal Experience
}

\section{Mario Ricca*}

ABSTRACT: The European Union was born under the sign of 'unity in diversity' and pluralism. Such a design with its rather oxymoronic combination of ends has so far found an institutional and procedural synthesis. From a cultural point of view, however, Europe is divided, and efforts towards anthropological translation, at least in as reflected by the law, have so far been very scant. This diffraction results in a legal pluralism that addresses the national cultures as if they were parallel entities and, just like in a Euclidean universe, doomed never to meet. This essay aims at opening a pathway to develop a European legal interculture, as an outcome of both anthropological-spatial understanding - chorology - and legal experience aligned with the needs of European citizens and amenable to support the project of a Europe whose 'unity' may no longer consist of reciprocal cultural indifference. A Europe that no longer shares a common space of justice but rather, precisely, shares an interspace of a common justice.

KEYWORDS: Europe - intercultural - translation - chorology - pluralism

\footnotetext{
* Professor of Intercultural Law at the Department of Law of University of Parma.
} 


\section{Prologue}

Europe is united, but the cultures within it are not. This is the current state and it certainly looks like something of a paradox. However, logical paradoxes often persist inside historical processes. Through the course of political and social development, the pace of change is marked by transformations, their phases, and the coexistence of contradictions. Sudden changes and revolutions before and after confirm the resilience of cultural habits, traditions, and previously established customs. The old and the new, the synchronous and the asynchronous live together in the traces of history. The European Union is a project, whereas the anthropological landscapes and the ethno-legal mentalities of people have already been cemented into place and have become realities. To make matters worse, these landscapes and mentalities are in no way homogenous. The ethno-political tensions especially within the nation states (such as Scotland, Catalonia, the Basque Country, Yugoslavia and also the antagonism between the south and the north of Italy) provide clear evidence of this lack of uniformity. What are the strategies deployed by European institutions to address these cultural discrepancies, these different imaginaries of subjectivity? What instruments have been devised so far to realize the ideal of 'unity in diversity,' that is the motto of European Union itself? How are such differences and the corresponding claims for justice combined and simultaneously addressed by European institutions? What are the institutional and normative devices used to reach these ends?

The answer to all these questions lie in a single watchword: pluralism. In this essay, I do not deal with the technical arrangements engaged by the communitarian institution in order to implement the steering wheel of 'pluralism'. Rather, I will try to cast a gaze on these tools - so to speak - from the outside or, at least, from a distance. Thus, I will not take into account the institutional technicalities in and of themselves, primarily considered in their procedural form. On the contrary, the subject-matter of my inquiry will be the 'raw material' of legal experience, that is: a) the socio-anthropological meanings "poured" or to be poured into the procedural engine; b) the methods employed to gather and transform them; c) the teleological congruence between their meanings, and the normative outcomes obtained at the end of institutional processes designed to induce the political-cultural integration of Europeans.

\section{The pyramidal approach to the Charter of Fundamental Rights of the European Union}

My argument takes its cue just from the proclaimed pluralist vocation of supranational legislation and its hermeneutical standards. I begin with the European Charter of Fundamental Rights and the interpretative activity of the ECHR. Subsidiarity (both vertical and horizontal), proportionality, and margin of appreciation are all standard/widely used formulas aimed at underpinning a pluralist application of the Charter. They join the assessment of the legitimacy of national laws which tries to be as responsive as possible to local demands. Now, I will not linger on a description and analysis of these hermeneutical standards. I will focus, instead on the pyramidal approach discernible in the interpretation of the Charter and in the use of its axiological and normative patterns.

As a rule, local differences are made to dialogue with the basis of Fundamental 
Rights by means of vertically drawn semantic coordination lines. The congruence sought between particular and general, local and supranational, resolve, in this way, in a poly-topic, or multi-local, disarticulation of the normative principles processed at the central level. All this takes place, unfortunately, without promoting any intercultural and horizontal translation between cultural differences, or between the different 'dialects' of social and legal subjectivity experienced by people in their own countries. The pluralist claim for the recognition and the protection of differences triggers a sort of antagonistic race to inscribe one's own cultural specificities (often, only postulated rather than argued) in the apical lexicon of European institutions. So, the heterogenesis of ends proves to be the crux of this approach. In the end, the proclamation and the end of 'unity in diversity' (notwithstanding the differences) ends up being converted into a form of pseudounion in reciprocal indifference. Moreover, this kind of indifference is perceived and rhetorically displayed as a sort of "optimum horizon," the very mirror of a pluralism that serves as a bulwark for the recognition of political and cultural differences. All this, however, is little more than an illusion, because that horizon is simultaneously made unreachable by the pressures towards homologation prompted by countries that are more powerful politically and economically. A homologation that, in turn, impacts on the style of interpretation of fundamental rights and, as a cascade, also impacts on the categories of legal subjectivity so grafted by institutional means onto the social practices of the whole of Europe.

This undoubtedly represents the outcome of a deficient vision of European integration. An integration that seems from the outset to give up on a process that strives for translation/transaction between the anthropological landscapes of the various peoples of Europe or their expressions of legal subjectivity. And yet, in the absence of translations and transactions of these Europeans' cultural encyclopedias, achieving the goal of creating an interculturally fashioned legal and social subjectivity will be impossible. Regardless of any legal intercultural process, and until the semantics of quotidian coexistence are not inflected by it, European people cannot effectively participate in a common citizenship. This is so also because citizenship is not exclusively a matter of formal awards, labels, public repertoires or certificates. All these 'materials' should be considered not as premises but rather as consequences, as political-bureaucratic results stemming from anthropologically shared practices and coming from the unfolding of individual agency merged into the stream of quotidian life..

Creating an interculturally devised grammar of European subjectivity requires an interdisciplinary effort. The legal systems of diverse nation-states must be involved, to begin with. To assume that it would be possible to embark on such an endeavor without a careful assessment of the member states legal systems and their differences is purely chimerical. Any pathway of cultural cohesion must come to terms with the law. In the absence of such coordination, any true effectiveness would be hopeless. Culture inhabits symbolic imagery but also pragmatic experience alike. Ideas, thoughts, have consequences; as they morph into practice, that is, actions and behaviors, they inevitably bump into laws, and into institutional and social norms. To align the efforts of cultural translation with legal standards becomes consequently an inescapable prerequisite. Otherwise, the law will be deaf to intercultural endeavors and it will work as an obstacle to cultural change and act as a censor, inevitably conservative and nationalist, against any project with integration aims.

On the other hand, comparative analysis, if strictly limited to positive data, will be likewise insufficient. Joining Europeans is not the same as simply comparing, 
overlapping or adjusting their merely normative diversities ${ }^{1}$. Persons are not norms - fortunately. On the contrary, norms are designed to formally precipitate traditions of justice, shared mentalities, anthropological patterns, ethical standards, customs etc., all forged and at the disposal of people in service to their ability to plan their own actions. All of this 'symbolic matter' is much more malleable than the normative assertions, even if it is the very source of them. Not surprisingly, people, on average and especially when they wander across national borders, are not so much concerned with the preservation of their previous normative apparatuses, but rather with the possibility of retaining their underlying weave of sense, even if transformed. This is because there are very few people, in everyday life, that respect the law because they know it. The ignorantia legis non excusat principle does not work because it is rooted in the actual and direct knowledge of formal normative apparatuses.. In fact, that principle — in itself quite absurd relies on a total correspondence and practical convergence between law and culture, normative sets and customs, legal rules and habits of life. Legal norms owe their effectiveness to the underlying presence of behavioral habits coextensive with the contents of legal apparatuses and ubiquitous among people. These habits are steadily at work as a hidden or mute part, and yet they are indispensable to the legislation of every country. They are the backdrop and the prerequisite for the effectiveness of the rules enacted by institutions.

When norms confront processes of socio-cultural de-contextualization, their chances of effectiveness inevitably decline. If cross-contextual knowledge of cultural backgrounds (tacitly presupposed by the diverse legal systems) is lacking, the chances of unearthing common ground, of engaging in translation and transaction between the legal apparatuses, becomes almost impossible. The horizon of normative languages, considered in its formal sense, reveals only what is already visible: the words inserted into laws are the sole guarantee for the correspondence between culture and institutional rules. Any changes, adjustments or re-molding of the linguistic-normative tenor therefore morph into the danger of cultural break up. The possibility of managing the integration process among different people through comparative analysis and inter-normative interpretation thus proves to be an unenforceable enterprise, doomed to fail or at least to result in flawed outcomes.

The history of attempts by European institutions toward normative unification or alignment between nations launched via contracts, inheritance or family laws and so on, is a path studded with failed attempts. After all, when the rigidity of norms is taken to be the sole expression of a whole culture, to compromise or give up that rigidity is necessarily felt as a self-damaging act targeting one's own identity. Thus, the inherent rigidity of legal languages ends up answering the analogue 'stiffness' of ideological tenets. The challenge of a culturally transactional integration under these conditions looks lost from the start. For precisely this reason, a successful translation between legal systems requires observing them through a historical-anthropological lens. For this purpose, a process of immersion in the different mentalities, following the traces and the historical features still resilient within and beneath the current legal settings, is fundamental,. That which is to be translated, and is actually amenable to creative translation/transaction, coincides with the habits, the underlying keys of sense, reflexively re-interpreted by

\footnotetext{
${ }^{1}$ With regard to the 'institutional fashion' (but lacking of any anthropological referral) of theoretical efforts oriented to conceptualize pluralism in European Union, see Giuseppe Martinico, The Tangled Complexity of the EU Constitutional Process: The Frustrating Knot of Europe (London - New York: Routledge, 2013), 23 ff. and ibidem for an interesting critical review of literature about this topic.
} 
the parties involved in negotiations for political and inter-normative harmonization. But, without an adequate historical awareness and a skillful anthropological review, the subjects requested to manage the translation/transaction processes will inevitably end up stranded on the shoals of sterile wars struggling for the single word to use, in turn perceived as a blazon and a banner of the identity of each of the parties ${ }^{2}$.

The exhausting iterations of useless negotiations often lead European institutions to take two apparently opposite approaches. Homogeneous normative solutions, which are in reality fictions of a sort, since they lack any integration, may be imposed — if at all — from above and authoritatively. In these circumstances, the power of authority shows its Gorgon's features. The more powerful nationstates avail themselves of their ability to influence political choices. This, however, is not always a viable solution. When there are many fronts of diversity, marked by a strong symbolic desire for identity, the strategy used is generally different. Under the rubric of pluralism, European institutions enact normative provisions that allow each country the possibility of preserving rules, jurisprudential veins, institutional practices and habits of legal subjectivity that are substantially differentiated and parallel. Nonetheless, both strategies - very frequently adopted - give rise to two essentially convergent questions.

Faced with normative unification managed and imposed from above, what will become of the cultural differences engrained in the daily life of European people and not legally recognized? Are we to think that they will vanish in a whisper, merely evaporating? Or, rather, will those differences continue to live parallel lives, perhaps hiding in the shadows of the official legal practices? Or, instead, within the inconsistencies of the formal norms so as to produce a sort of heterogenesis of its less acceptable effects?

Often, inside local dimensions, European provisions characterized by homologating consequences undergo some transfigurations. These occur simultaneous to their implementation within contexts connoted by the sociocultural variables idiomatic of each area.

Conversely, is not the radically pluralist solution - even if only in appearance - that commits some areas to autonomous regulation by individual national institutions likely to engender a disaggregated Europe? And is not such a lack of coordination, alongside the absence of a common lexicon for European legal subjectivity, in danger of letting the normative schemas framed by the more powerful countries prevail, at least in the long term? A danger that could affect all the situations in which individuals from different countries interact? The occurrence of such an eventuality, tied to the overlapping of different subjectivities and spatial dimensions of law, has a precise legal-geographical, indeed 'chorological' determinant. I will address it below. ${ }^{3}$.

\footnotetext{
${ }^{2}$ Anthropological research has not been a part of the development of the European community. More recently, some scholars have focused on the construction of European identity through cultural-political instruments managed from above. The psycho-social dimension is instead understood in two directions: the relationships between the cd. Eurocrats, i.e., officials of different cultures involved in Community institutions, and the rights of cultural and/or linguistic minorities scattered across different national contexts. However, the problems related to inter-normative translation, considered on a large scale as an essential counterpart of political-cultural integration, have remained privy of an anthropological perspective. In this regard, see Andrés BarreraGonzález, Towards an Anthropology of Europe: Outline for a Teaching and Research Agenda, in Anthropology of Europe: Teaching and Research, ed. Petr Skalník (Prague: Set Out, 2004), 3-25; Lisanne Wilken, Anthropological Studies of European Identity Construction, in Companion to the Anthropology of Europe, ed. Ullrich Kocjel et al. (Malden (MA) - Oxford - Chichester: Wiley-Blackwell, 2012), 125-44.

3 About legal chorology, see Mario Ricca. Sussidiarietà orizzontale e dinamica degli spąi sociali. Ipotesi per
} 
At this point, it is important to underline that the "do it yourself" pluralism, meaning nationally defined choices in legal policy, may prove illusory. This is so because people and their own interests cross nation-state borders continuously, making the territorial edges of sovereignty irrelevant. Considering this circumstance, the idea that when at home everyone does what is most comfortable to his culture, imagined as a kind of entity isolated from the rest of the world, may prove to be a completely misplaced concept, detached from historical reality and fundamentally unworkable. Political isolation and cultural disaggregation could turn out to be, in short, losing strategies, both economically and in terms of the concrete establishment of ethno-cultural rights. The rhythms of transnational inter-subjectivity could trigger dynamics of a one-way inter-constitutionality. They would proceed, in all likelihood, from the more powerful countries towards the weaker ones, but not vice versa. In one shot, both projections of pluralism would be betrayed. I refer respectively to the infra-state pluralism, and the exo-state pluralism that is attuned to the global dimension of the cultural, political and economic experiences undertaken by different subjects of law. In the name of the ethno-ethical flexibility recognized by Europe with regard to national legal policies, nation states would find themselves virtually enabled to crush internal minorities including, of course, those present as a result of migration flows ${ }^{4}$. At the same time, the same national states and their dominant groups would ultimately suffer the effects of a counter-homologation factor set in motion by the transnational dimensions of individual experience subdued to the normative patterns enforced by the stronger countries to regulate and control the interests circling around them.

As a partial answer to the questions and doubts advanced so far, the protection of the so-called 'essential core,' the kernel of rights provided by the European Charter of Fundamental Rights, is often invoked. According to this principle, both in the case of the solutions imposed from above, and in the case of self-determination at the state level, violations of the core of fundamental rights would be countermanded. But the definition of 'the core' is already difficult enough in itself without inviting cultural difference issues to the table ${ }^{5}$. Indeed,

una corologia giuridica, in Il principio di sussidiarietà nel diritto privato, I, ed. Mario Nuzzo (Torino: Giappichelli, 2015), 15-77; Id, "Uso interculturale dei diritti mani e corologia giuridica," Humanitas 69 (4-5 2014): 734-50.

${ }^{4}$ Examples of states adopting policies and regulations strongly inspired by a kind of ethno-national localism are all too easy to find, even within the very jurisprudence of the ECHR regarding fundamental rights; they can be clearly seen throughout the argumentative arsenal used by Court, consisting of standards of evaluation such as "margin of appreciation," "principle of proportionality," and even the "principle of subsidiarity." See Marie-Bénédict Dembour, Who Believes in Human Rights? Reflection on the European Convention (New York: CUP, 2006); Alessandra Pera, The 'Margin of Appreciation' in ECHR Case-Law As a Boundary Line to Legal Transplants, in The Diffusion of Law: The Movement of Laws and Norms Around the World, ed. Sue Farran et al. (Aldershot: Ashgate, 2015, forthcoming.).

5 See Mireille von Hildebrandt, "Human Rights as preconditions of an intercultural society," in Selected Works of Mireille von Hildebrandt, accessed January 2010, http://works.bepress.com/mireille hildebrandt/28. In this essay there are references to the methodology to be used to avoid a 'vertical' and essentialist use of statements on rights. On the question of the "core" of rights, there is also the problem of the tension between the core of rights relevant to European citizenship and the fundamental rights and liberties of the European Union as defined by multilateral and multicultural readings. This tension has emerged as a result of the well-known ECJ decision Ruir. Zambrano. In this regard, see Hanneke van Eijken and Sybe A. De Vries, "A New Route into the Promised Land? Being a European Citizen after Ruiz Zambrano," in European Law Review, $36 / 5$ (2011) 704-21; and for positions favorable to the dissolving of this tension, mainly through systematic and institutional consistency, see Alessandra A. Silveira, "Diritto dell'Unione Europea: dimensione culturale e 
adopting a different cultural perspective often means decentralizing the gaze, deessentializing the process oriented to the construction of judgments, and thus restating the relationship between what is central and what is peripheral within each category currently used. Relying upon the principle of the inviolability of the 'core' of fundamental rights as an antidote to the shortfall of interculturality in the actions of European institutions might be compared to prescribing fasting to a patient suffering from malnutrition.

In the world imagined by Euclid with his fifth theorem, parallels are destined never to meet. Their fate is to proceed in space simultaneously and symmetrically but strictly independent, without any possible intersection. Similarly, cultural and legal pluralism as seen in the European Community experience - at least so far - shows a historical path of national entities programmed to maintain a mutually unbridgeable distance. Whether homologated or divergent from national laws and the cultural patterns underlying them, the legal cultures of Europeans seem to impede them from the possibility of meeting, thereby obstructing any possible efforts towards their intercultural translation.

Geometrical space, however, is not the same as historical and political space. If the political one can be imagined as empty, postulating for each parallel line a fixed distance from the other, the cultural and vital space, on the contrary, appears to be always populated and marked by the meanings attributed to what is occurring within it. The possibility of maintaining a fixed distance depends on the relationships of meaning that each line of conduct and the corresponding category used to symbolically represent it hold with all the others and with their connotations as well. The developing of these lines of action will therefore unfold through a space curved by the implications of meaning, by the symbolic and pragmatic connections that the same lines will interweave with each other. Therefore, it is up to these traces of involvement to determine what is distant and what is near, what is tangent and what is divergent, what intersects and what moves asymptotically.

The impossibility of conceiving a political and cultural vacuum not curved by relations of meaning, a space where each entity is isolated and conceptually separated from the other, suggests that interculturality occurs anyway, even when it is denied or not cultivated as a public end at the institutional level.

European unification may have played a part in generating some sort of political-geometrical illusion. The common European space was imagined as institutionally continuous, as if it had been already (culturally) homogeneous, a tendency symptomatically betrayed by the widespread rhetoric about the emergence of a European citizenship. This "European citizen" is indeed a figure obtained through a hyper-abstraction from the concrete political and cultural dynamics, and fashioned by ignoring the differences rather than translating and transacting with them (within inclusive interpretive and normative schemes). The fictitious homogeneity imagined by 'European citizenship' is, in all probability, the same ingredient that allowed the postulation of the existence of a uniform empty space, where every country, every culture, can be kept as a parallel entity as appropriate to a Euclidean space. In many respects, however, it is a mystifying representation, mirroring the image created by the rhetoric of globalization. And so what is proposed is a world of entities scattered through a space populated by incommensurable and reciprocal diversities which nonetheless undergo an

artistica in un contesto di intercostituzionalità,", in Arte e critica, special issue on Nuove Alleanze. Diritto ed economia per la cultura e l'arte, accessed 2014, free pdf download at \ www.decamaster.it, 72- 
unavoidable, though contradictory, process of homologation. In the case of a United Europe, conversely, it is a unification which has already taken place at the institutional level and which presumes a homogeneous space where differences can be configured and safeguarded as a projection of a pluralism orchestrated from above. Either way, in my view, the cognitive/cultural deficit persists and is caused by errors in the legal-institutional project planning and the strategies of political action. So, pyramidal/hierarchical interpretations of human rights, as well as the fundamental rights of the European Union, are exactly the opposite of what might facilitate intercultural translation and transaction processes. In order for these processes to take substance, it is necessary instead to think about the discourse on rights as an interface for translation between different cultural traditions and legal mentalities put in action by the various people of Europe as their everyday lives unfold within the changing spaces and inter-spaces of individual existence.

\section{Intercultural Uses of Fundamental Rights of UE and legal European Intersubjectivity}

The political imagination of EU institutions cannot seem to wriggle free from a logical hierarchical/ pyramidal outlook in its interpretation and implementation of human and/or fundamental rights even when spurred by the best intentions. For ample proof of this phenomenon one only has to read the White Paper on Intercultural Dialogue subtitled 'Living Together in Equal Dignity,' that was drafted in 2008, the so proclaimed 'Year of Intercultural Dialogue.' The entire text is crammed with references to diversity, respect for pluralism and mutual dialogue between the different European identities. The whole project, outlined by the White Paper, is intended to pave a path of integration that respects and includes cultural differences within the framework of human and/or fundamental rights. However, no mention is made in the paper regarding how to translate these differences, what methodologies are to be used to decipher them, how to generate patterns of transaction obtained through equivalences of meaning understood beyond the morphological diversities and their associated symbolic-identitarian stiffening. Even more importantly, this paper does not give any indication of how dialogue might be given a voice towards the development of normative parameters inclusive of the cultural differences at stake. Beyond the evocative and almost magical power bestowed upon the adjective "intercultural," there is little of any concrete value. Conversely, the hymn sung to difference, conceived as a value in and of itself by the Paper, seems to provide little more than background music to accompany the ongoing reciprocal indifference among European peoples.

With the universality of human and/or fundamental rights and the semantic vagueness of their enunciations as a backdrop, every group and every individual can claim their own exclusive identity to be subsequently negotiated in the arena of political-institutional confrontations. The result of these negotiations in normative terms, however, can only consist of a solution with a dual output: a) serializing and homogenizing solutions, devised according to the preferences of the most powerful; b) nomothetic devices inspired by procedural justice, through which everyone can self-determine within a very vague framework. In other words, we have the triumph of Euclidean political geometry or, rather, an oxymoronic "plane of parallel convergences".

The White Paper on Intercultural Dialogue actually says very little about law and normative solutions. In any case the editors of the document, not lawyers but experts of intercultural processes, could raise a counter-criticism to my remarks. 
They could reproach me for promoting a law-centric vision of intercultural relations, while they would engage, instead, on a cultural level, precisely that of the free exchange of ideas, creativity, and arts. I could, in short, be accused of having a narrow vision worthy of a bureaucrat, constrained to think of politics as a mere hotbed of institutional and legalistic cages for curtailing human experience, rather than a cultural phenomenon. However, as will emerge from the pages of this paper, there is no need to convince me that intercultural dynamics are to be managed first and foremost on an anthropological ground rather than on a legal one; or, to put it differently, that anthropological-translation processes must come before any determination of the content of intercultural law provisions. The most relevant question, however, seems to me to be another.

I think, and I have also ascertained it through field research, ${ }^{6}$ that intercultural processes are likely to remain inconsequential in the absence of specific support directed to urge normative agencies to listen to claims resulting from cultural difference. As long as the law remains deaf to the demands coming from intercultural experiences, it runs the risk of perishing on paper. However, if we are to fill legal forms with intercultural substance, specific intercultural methodologies are necessary to forge a path through a legislative planning process that can assure their transaction within inclusive conceptual and legal frames; the contextualization of cross-cultural differences, via a process of anthropological translation, is fundamental. In short, to effectively enhance intercultural dialogue, European institutions must take part in the birthing of intercultural law and, even before, the elaboration of nomothetic techniques required to imagine and realize it.

Although it may seem paradoxical, hanging the realization of a European area of intercultural coexistence on the aprioristic universality of human and/or fundamental rights is exactly the opposite of what might serve its purposes. Every culture has the theoretical possibility of being mirrored in the spectrum of semantic statements of rights or, at least, the ethical principles that they recall. After all, who does not recognize in the ideas of equality, fraternity, and justice, a respect for people and their dignity, freedom, equality, and so on? The problem lies in the fact that these ideas are subsequently interpreted very differently according to cultural glasses worn by each community or individual, spatially and historically situated. Even considering only the European scenario, taking a common constitutional heritage for granted means little if the practical implications of 'fundamental rights' are not attentively reviewed. On the other hand, these implications are intertwined, in both a semiotic and pragmatic sense, with conceptual schemes acted out by people in different contexts. These are the same conceptual schemes that can be found formally transfigured in the different traditions of statutory laws that regulate the daily life of people by means of the various legal institutes. Human and/or fundamental rights gain their significance and practical implications because of the adjustments taking place between the semantic spectrum of their statements and the contents of the laws in force in different countries. Inheritance laws, contracts, crime laws and so on, take on a cultural bent and a normative substance that is very different in each of the countries of Europe - which itself is nothing compared to what blatantly emerges when you cross the borders of the Old Continent. As long as a serious commitment to translate each of these cultural habits, and the legal institutes that engage them normatively, into another is lacking, efforts to invoke human and/or fundamental rights in the hope of getting intercultural dialogue to flourish will come to nothing. Rather, each of the countries involved in this endeavor will end

\footnotetext{
${ }^{6}$ See above note.
} 
up identifying its own legal and cultural tradition as the prototypical implementation of human and/or fundamental rights ${ }^{7}$. Consequently, any national legal system will consider possible differences from their prototype as unacceptable as if they were evidence of inhumanity. Resting on these assumptions, any proposal of intercultural transaction will appear as an unjustifiable attack on their identity. The semantic stiffness of rules, then, will bring the rest to completion. Finally, the intercultural transaction will end up being conflated with the inter-normative transaction or, better, with the ordinary 'untransactability' of normative contents. At that point, authentic wars will erupt in order to establish the 'true meaning' of human and/or fundamental rights and their corresponding more suitable (prototypical) implementations through the institutes provided by the national statutory laws.

But is a different and perhaps more effective approach to the challenges of intercultural European integration and its legal and institutional implications really within reach? I am inclined to give an optimistic answer. I think, however, that to set off in the right direction, some assumptions must be outlined.

a) Inter-legality as interculturality.

The starting point for a genuinely intercultural declination of the motto "unity in diversity" should be the idea, and subsequently the belief, that the inter-legality between European countries-also in the form of inter-constitutionality-is synonymous with interculture. This assumption implies that it is not possible and that is to be considered a useless effort to find common legal platforms before common cultural platforms have been identified. As a corollary of this argument, we should introduce the postulate that without a prior survey conducted in anthropological depths (and, therefore, historical-geographical ones, too) the creation/invention of common laws ${ }^{8}$ in any set of legal areas would be in vain, or at least damaged by significant cognitive and informative deficits. What must be integrated first and foremost are the people, not the rules. Cultural habits are much more flexible than forms and legal statements, despite the fact that the latter are intended as a sort of projection of the former. Furthermore, people have political agency, the rules in and of themselves do not. If questioned, normative statements remain silent or otherwise express only what their interpreters say on their behalf. In other words, the rules themselves cannot go beyond their reciprocal and textual diversity. That is why the technocrats engaged in EU legislative planning committees should look beyond the rules, and instead draw on mentalities and customs, put them and their owners in dialogue, even better through anthropological-legal surveys. This should be their actual area of research in the pursuit of a horizon of integration. Sitting at the table, trying to translate and compromise texts as if they were the essence of the people, namely the future subjects of rules intended for 'Europeans,' is likely to produce few results and, indeed, is likely to foment the welding together of ethnic-identitarian and normative rigidities.

b) Intercultural methodology. Narratives, crossed-contextualizations, translations/transactions.

Once the interdependence of both legal analysis and anthropological insight of the intercultural horizon are a given, we must identify how this 'tandem' should be

\footnotetext{
${ }_{7}$ See Xenia Chryssochoou, Cultural Diversity: Its Social Deiversity, (Malden, Mass. - Oxford - Carlton, Vicatoria: Balckwell, 2004); Costas Douzinas, The End of Human Rights: Critical Legal Thought at the Turn of the Century, (Oxford - Portland: Hart Publishing 2000), and Hildebrand, Human Rights.

8 The formula 'commons laws' is inspired by Patrick H. Glenn, On Common Laws, (Oxford: Oxford University Press 2005).
} 
articulated in procedural terms and what its object should be. In this regard, it must be considered that any form of inter-normative translation must undergo, in a particular and accentuated way, the same limitations that characterize linguistic translation. Each linguistic utterance and its use rest on contexts of experience impossible to transfer point by point (or matrix by matrix) each upon the other. The equivalences of meaning always involve transformation. This, however, does not necessarily constitute a loss, but it is rather the engine of the translation process. To translate is to transpose the Other's experiential dimension into one's own experience. But 'transposition' does not mean mimetic annulment. Throughout the effort of translation, the Self or the translating culture has to maintain its own Otherness. Moreover, in the case of legal translation, especially when utilized to accomplish legal transplants, the maintenance of the identity of the translator enlivens the process with even more vivid axiological colors. The language used by the law has very tight constraints of semantic pertinence. This is because with regard to the law, every option for using a particular word corresponds to precise value choices conveyed by political decisions and endowed with immediate practical consequences. To understand why the law of a particular country uses one or more specific words to name and define a given behavior requires an investigation into the historical-narrative paths that led to that choice.

The first step in tracking down semantic platforms useful to managing processes of inter-normative transaction/translation involves the production of narratives that involve a cross-cultural history of the individual institutes. The history of the words used must be retraced, however, by the right means, if we are to penetrate the plots of cultural anthropology. This operation can provide the precise building blocks for the next activity of intercultural translation/transaction.

The second step, just subsequent to the narratives crossed-but only in logical and certainly not chronological terms, since the two actions overlap in practice-is the cross-contextualization of narratives made by the cultural actors involved in each case. Understanding (but also processing) a narrative actually requires a work of contextualization and inter-contextualization. And it is so simply because no one can map the contexts of meaning encapsulated in the narratives of Others without employing elements from their own contexts of experience and knowledge, their own semiotic framework. Nonetheless, there is a way to avoid the risks of domesticating or ethnocentric interpretations, stemming from the false assumption that one's own conceptual schemes are universal or 'natural.' This is to use contextualization as a reflexive key, by drawing out elements to question, decipher, and urge the other actors to enrich, integrate, and specify their selfnarratives. ${ }^{9}$. Such a task must necessarily be pursued in a bi- or multi-lateral way. Without a shuttling effect, coextensive with the game of reciprocal questions and answers, a false representation of the Other's mind and culture would be impossible to overcome. As the parties produce more detailed narratives, behind every single word or phrase a network of semiotic relations will begin to take shape. What is important to emphasize is that the narratives created on each side of the translation process will have specular features because they will be imbued with cultural contexts and connotations expressed on the other side. More directly, an Englishman will describe himself to a Chinese person very differently than he will to a Ghanaian. Intercultural processes are a prism in which even the

\footnotetext{
${ }^{9}$ For bibliographical references about this topic, see Mario Ricca, "Intercultural Law, Interdisciplinary Outlines: Lanyering and Anthropological Expertise: Before the Courts," in E/C, accessed March 3, 2014, www.ec-aiss.it, 1-53; Id. Culture interdette. Modernità, migrazioni, diritto interculturale, (Torino: Bollati Boringhieri 2013); Id, Oltre Babele. Codici per una democrazia interculturale, (Bari: Dedalo 2008).
} 
knowledge of the Self acquires different facets depending on the interlocutor, the situation, the time, and so on.

These efforts of cross-contextualization, together with an increased number of narratives, provide semantic landscapes which gradually become richer and better articulated. By using them as a starting point, it will be easier to trace the conceptual connotations that can work as axes of equivalence between the categories used by languages and cultures in comparison, and to engage in intersubjective dialogue. The emergence of a set of semantic connotations likely to function as a bridge will generate progressively inter-contextual categories, engendering a kind of 'third space' which is yet continuous with semantic devices and apparatuses originally used by the interlocutors.

The characteristics of 'thirdness' or innovation on one hand, and the continuity with the past on the other, coexist because the representations of their differences, the very awareness of them, is not immune to cultural conflict, to the strain of translation. That is, the differences postulated at the beginning of the process are simultaneously transformed and clarified through the efforts to translate, understand and be understood by the Other. All of this suggests that translation is a cognitive activity with a highly creative component, and therefore a political one too, especially when it results in practical effects that are immediately applicable.

The creativity inherent in the translation process aligns itself to metaphorical invention. As in metaphors, trans-lation transposes the meaning of a word into and over another. In so doing, however, not just words but also contexts of experience are blended. The inter-contextual dimension that results is therefore also an inter-spatial dimension, which will serve as a background for understanding the significance of the actions taken by the parties as an outcome of intercultural exchange. Furthermore, it is a new dimension, previously non-existent, where each of the initial contexts of meaning and their categorical boundaries will gain some new elements or connotations and lose others. The words chosen for the final translation will constitute only the tip of the iceberg of the set of semiotic relations (composed of symbols as well as actual or potential experiences) drawn out by the work of creating the new intercultural context. Translation and creative and / or political transaction will then reveal themselves as two ways to define a single process. One might wonder, at this point, whether the inter-contextuality, and its corresponding inter-spatiality are only the result of intercultural translation efforts or perhaps are reflective too of a pre-existing situation in some way.

c) Space and culture. The legal chorology. The answer to the implicit question raised at the end of the previous paragraph constitutes the third assumption which is, in my view, indispensable to an intercultural integration suited to involving the legalinstitutional dimension as well. To elucidate the point, I will propose some questions which may appear to be against the flow of my argument. They showcase those arguments that might be employed by a "devil's advocate" interested in delegitimizing intercultural dialogue.

Could inter-normative syntheses between the legal traditions of the different EU countries be managed by a hierarchical and/or systematically procedural method according to fundamental rights? Should EU institutions, after a proper examination of differences identified with a legal view, impose uniform solutions capable of ensuring a European area of justice endowed with consistency and stability? Would stability thus achieved ensure legal certainty and a chance to provide security to the movements of people and things within the territorial circuit of the EU? And where this homogenization is not possible even by promoting progressive rapprochements of the national laws, could the EU make 
room for solutions inspired by procedural justice and, therefore, oriented to a decentralization of powers, so as not to prejudice the cultural specificities of each context? Should the exercise of power and authority by EU institutions be used as a device to overcome the political paralysis caused by forms of defense "to the bitter end" of cultural specificities that are often speciously invoked for the sole purpose of legitimizing identitarian antagonisms or selfish and short sighted particularisms?

My answer is that the European space is already a cultural and pragmatic interspace. Until the recent past, the harmonization of relationships between the nations and peoples of Europe had as its main focus the arrangement of interests perceived as worthy of consideration at the level of state institutions. This is not to say that those interests had no impact on people's lives. I only point out that citizens and individuals belonging to nation-sates would have only indirectly and remotely perceived the disadvantageous or advantageous implications of a centralized management of those interests. Probably, it was a misleading illusion. Nonetheless, the need for peaceful, coordinated policies designed for cooperation rather than conflict and pertaining to a macro-systemic dimension was reserved to government agencies. The gaze of individuals, trained on everyday life, did not, for example, aspire towards a rapprochement with national laws in certain areas as a crucial determinant of their vicissitudes and the fate of their affairs. Indeed, if anything, customs and inurement to their traditions has made it rather difficult for national populations to accept changes imposed from above and pursued as a response to these kinds of concerns.

Of course, in the eyes of governmental operators, the interrelationship between law policy options astride the borders of states and the national welfare could also appear much more clear and compelling. However, government agencies must also respect the constraints of representation and, therefore, approval ratings affecting their elections or re-elections. The gap between their representation and the expectations of citizens has also ended up having an impact on effective management policies for European integration. Needless to say, the shortsightedness of citizens could also be a form of 'myopia' due to an inability to understand the relationship between their legal and cultural practices and the overall impact they have on a transnational level in terms of political, macroeconomic, and other similar effects. In democracies, a sort of 'refusal to look beyond' may often colonize the avenues of consent, however the people-unless better solutions are devised-are always the owners of sovereignty and their right to exercise it by voting.

Besides, he who does not know, does not see; and he who does not see, does not want to see. That someone is unable to see or predict something, however, does not imply that it does not happen anyway if it is part of the plot of the phenomena. Thus, only when something has happened-and sometimes not even in that case-will it become clear that the people did not know the meaning behind their decisions for the simple reason that they were unable to properly represent the scope, the conceptual and spatial perimeter of their consequences. To not know the consequences of their actions or choices, however, means not knowing what the actions themselves mean. But the meaning of any object or phenomenon, reduced to a category of interpretation, can be understood by examining a list of its implications. These implications, included in the checklist that defines each category, become categorical or conceptual connotations ${ }^{10}$.

10 The ongoing transformation of the implications (also those springing from experience) in categorical connotations is coextensive with a radial conception or understanding of categories, 
Knowing something-be it phenomenon, object or word-means therefore learning to imagine even its pragmatic implications, the same ones that are produced through the space of experience and mold it. In many respects-thus returning to European political issues-if nation-citizens did not grasp the connections between the local and the transnational before, the connections between their own behavioral patterns and their spatial implications, then not only were they unaware of the actual meaning of their own culture and laws but even of their existential geography.

The considerations just laid out are useful in demonstrating the continuity/coextensiveness between word and space, between categorical frames and spatial boundaries. This continuity depends on the phenomenon in which, during the production and perception of meaning and sense, those frames tend to be transformed into boundaries, and vice versa. Experience tends to put both the categorical perimeters and the spatial borders under constant stress. It urges people to develop new meanings to solve the problems posed by the environment and its mobile and liquefying vital barriers. In so doing, human beings use imagination and fantasy, producing genuine migrations of connotation or semantic implication from one categorical spectrum into another. Somehow, they trans-late, so that connotative elements migrate from one categorical context to another, generating cognitive metaphors, that is, new lenses for looking at the world and experiencing it. Humans use knowledge already acquired, then re-articulate it, manipulate it, and in this way create new possibilities, new forms of experience. Human action, driven by new patterns of knowledge, however, is projected into space by reshaping its boundaries, connecting the elements that defined previous connotative semiotic relations and phenomenal connections in new ways. All this does not occur, however, in a vacuum, but rather in the same space that the symbolically-oriented action is simultaneously shaping. It forges that space using imagination and fantasy as chisels for unearthing the continuity between the frames connotations present in discrete categorical frames and disagreggating connotative sets previously represented and experienced as they were packaged into conceptual units ${ }^{11}$. Everything unfolds along a stream of transformations and metamorphoses that take form from the semiotic space populated and constantly put in motion by the still unmapped flows of connotative indices. That primogenital space, and yet perpetually coexistent with the categorical cosmos that fuels its metamorphosis, corresponds to the Platonic "Kora"12. Its' analysis, of its

different from Aristotelian theory of essences. About the radial approach to categorization see George Lakoff, Women, Fire, and Dangerous Things: What Categories Reveal About the Mind (Chicago: The University of Chicago Press 1987).

${ }^{11}$ For a critical analysis of the theoretical-epistemological frame of such considerations, especially in the field of critical geography, see the essays included in the followings texts: Ben Anderson and Paul Harrison, The Promise of Non-Representational Theories, in Taking-Place: Non-Representational Theories and Geography, ed. Anderson and Harrison (Farham-Burlington: Ashgate, 2010), 1-34; Stephen Daniels et al., eds., Evisioning Landscapes, Making Worlds: Geography and Humanities (London-New York: Routledge, 2011).

12 See John Sallis, Chorology: On the Beginning in Plato's Timaeus, (Bloomington: Indiana University Press 2009). See, moreover, Derrida's insights in Plato's chóra: Jacques Derrida, 1993, Khôra, (Paris: Galilée, 1993); even if the deconstructionist approach and its post-modern endpoints lie at the polar opposite of my conception of chorology and its possible legal uses. Some further insights, closer to my rendering of chóra can be found in Julia Kristeva, Revolution in Poetic Language (New York: Columbia University Press, 1984) and in the related distinction between symbols and signs. Actually, my approach to chorology derives from the combination of Peirce's semiotics with the investigations carried out within critical geography and, recently, legal geography. See respectively: Gunnar Olsson, Abysmal: A Critique of Cartographic Reason, (Chicago-London: Chicago University Press 2007); Id., Mapping the Taboo, in Envisioning Landscapes, ed. Daniels et al., 34-43; Anderson and 
own reality, dual and coextensively semantic and physical, ideal and material, eidetic and experiential, is the 'chorology'. And it is exactly a legal-chorological perspective that can justify and open the pathway towards intercultural integration within Europe, and the world. It enables us to figure out the ongoing change of pace in the way people perceive political space within the EU. I will try to briefly explain why.

What Europeans even recently have hardly been able to understand and accept, that is, a space of experience beyond their nation-states, now seems to have become an asset, perhaps sometimes criticized, but in any case acquired through the imagination and action of all. From this very moment as well as retrospectively, it's hard to say what has come first: the development of an area of trans-national experience or the symbolic representation of the actions that produced it. Probably both have been emerging at the same time, slowly spreading awareness of a new political and existential space-even if, perhaps, without a shared consciousness of its production through the cumulative succession of seemingly unrelated individual actions. This silent but pervasive phenomenon, resembling the restless swarming of an anthill, has slowly reconfigured the space, enlivened by the increasingly frequent and intense transit of people, objects, capital and interests that mark the meaning and destiny of individuals throughout Europe today.

An increasing number of people enter into contracts, buy real estate, work, launch businesses, create relationships, etc., while straddling national borders and crossing and recrossing them continuously. Along their new routes they feel, more than ever before, the weight of cultural differences, ethnic traditions, and the ethical and legal mentalities experienced over time in each country. Through the lens of this greater understanding, they "see" the implications of the ultra-local, ultra-national dimensions of the choices taken and implemented "here and now," the inter-spatial scope of the conceptual and axiological paradigms used for operating them, the chorological projections of the representative schemes utilized to calculate consequences and, therefore, the sense of their actions. This renewed "seeing" motivates a number of their initiatives but it is also the consequence of them. The redefinition of the categorical

boundaries and the frames of meaning that supply this chorological vision develop into a perception of new spaces and result from new ways of "translation" of and between different peoples across multiple and previously inconceivable contexts.

The ability to seize the semiotic implications of actions previously unnoticed is the quintessence of intercultural translation and also its axis of legitimation. The answer to the questions raised above by the Devil's Advocate against intercultural law lies in this precise capacity and its indispensability for mapping the real context of the projection and implementation of individual and collective purposes. An effective dialogue between European cultures undertaken through an intercultural approach to legal experience within Community spaces should be read as the inevitable outcome of an acquired awareness. This precisely concerns the platforms of relations among the manifold phenomena that orchestrate the ongoing polyphonic intertwining of individual, local and particular vicissitudes.

Harrison, "The promise," 1-34; and, for legal geography, David Delaney, The Spatial, the Legal and The Pragmatics of World-Making: Nomospheric Investigations (Abingdon-New York: Routledge, 2010); Irus Braverman et al., eds., Expanding Spaces of Law: a Timely Legal Geography, (Stanford: Stanford University Press, 2014). In any case, 'chorology' is a term that belongs both to the geographical tradition and philosophical thought, even if with different connotations: see Kenneth R. Olwig, Choros, chora and the Question of Landscape, in Envisioning Landscapes, Daniels et al., 44-54. 
Developing an accurate chorologic vision of the socio-political dynamics of the EU area is the keystone of an epistemological analysis regarding the relationships between interculture and law. From this point, it is fairly easy to see why intercultural translation between different cultural "Others" becomes a prerequisite for understanding the implications of planned national legislations. The exercise of individual State sovereignty as well as of personal autonomy only make sense if they are able to gauge their consequences, and therefore their meanings, and of course the subsequent reactions and countermoves of Others. Seeing, translating and transacting with the Other than Self means, in other words, knowing the Other of Self that results from the inevitable interaction between one's own actions and those of others. Coexistence in a common chorologic weft makes Otherness part and parcel of each one's Future and, at the same time, makes the intercultural translation/transaction synonymous with foreseeability.

Now, the law punctuates the lives of all European populations, insinuating itself down into the most minute folds of individual actions. Deciphering it through the kaleidoscope of its cultural differentiations will not be possible without an effort towards anthropological weighting. On the other hand, the cultural grammar of European populations is strictly controlled through the sieve of legal qualifications. It follows that intercultural dialogue and inter-normative dialogue must go hand in hand, to avoid the inevitable failure of both. To achieve this, it is necessary, however, to employ a translation methodology that takes a 'horizontal' rather than a hierarchical/pyramidal approach, and has an inclusive attitude towards human and/or fundamental rights. Since intercultural dialogue and inter-normative connections must go in pairs, it follows that the translation between the legal frameworks of the various European countries in relation to specific areas should be conducted and gauged according to the problems and chorological-cultural exigencies of the people. Intersubjectivity, with all of its routes and its plots, has to be pointed towards an analysis that crosses cultures and rights, if common and inclusive legal-cultural platforms capable of germinating a European area of justice are to develop.

Placing emphasis on inter-subjectivity and its topical events is crucial for effective intercultural translation. Processing, exchange, and the comparison of narratives and crossed contextualization are not purely objective or mechanical tasks. The gaze upon the Other, on the meshes of meanings and experiences underlying its language, its history observed anthropologically, is not a matter of mere recognition. What is seen and surfaced does not speak for itself. The answers that emerge from the process of narration/contextualization depend on the questions that are asked. These, in turn, are influenced by the problems one means to solve, by the way they show themselves, and are then influenced by the phenomenology of the present time and the representations that their interlocutors will offer. As mentioned above, without an interdisciplinary and historicalanthropological examination of experience and of the normative apparatuses involved in intercultural confrontations, translation will be defective and will lead to outcomes characteristic of Euclidean pluralism (as defined previously). The investigation of the past and, therefore, the past itself, will not be immune from the shadows projected on it by the present. It will say only what is asked of it, and what is asked will be, in turn, the consequence of the grafting of signs and imprints left on the present from the memory and knowledge of diverse peoples. The objectivity of the historical-anthropological gaze is, in short, inevitably circular and dynamic, just like any semiotic relationship between a subject and an object of knowledge. 
Unfolding connotative landscapes as semiotic outcomes of crossed narratives/contextualizations is useful because it allows the overcoming of purely morphological differences and gives voice to 'mute parts', namely the implicit linguistic and behavioral representations displayed by the dialoguing parties included in and overshadowed by words.

In many cases, the incommensurability of cultural indices and also of the corresponding normative sets is the result of representations and evaluations of Otherness, of its codes. Both are developed starting from one's own cognitive schemas and gauged in accordance with the production of morphological connotations and appearances masquerading in an ethnocentric mantle of objectivity. After all, most intercultural conflicts stem from the overemphasis put on particular morphological profiles, typically the most conspicuous and easy to grasp, and from their metonymic use. They are taken as parts capable of representing the whole, a substitution which produces predictable reactions to Otherness. When this occurs, carving out interfaces open to translation and transaction from the stiffened weave of encounters becomes very difficult, if not even impossible. Indeed, the same attempt at dialogue verges on becoming completely useless, if not counterproductive because it only serves to ingrain mutual prejudices even more deeply.

To overcome similar 'idling predicaments' of intercultural experience, it is preferable to circle the issue and work on the 'mute parts' ${ }^{13}$, that is, all the relationships of meaning underlying morphological appearances. To advance in this direction, the historical-anthropological approach reveals itself to be essential and extraordinarily effective when coupled with the practice of crossed narratives/contextualizations. The connotative landscape underlying morphological indices is amazingly rich from a semantic point of view and is capable of showing axiological, teleological and experiential continuities between cultural habits, otherwise doomed to remain unsuspected. It allows words, precepts, and gestures to be situated, while identifying their possible genealogies of sense. This inter-semiotic cultural play enables a simultaneous deepening of knowledge of both the Self and the Other, giving birth, already through its creation, to new intercultural ground. Of course, the production of this ground of intercultural continuities implies neither an agreement nor an automatic evaporation of possible divergences. Rather, it agrees to create a cooperativelybuilt lexicon useful for the qualification of reciprocal differences (which, however, will never remain the same as when first perceived).

It is precisely at this stage that the intercultural use of human and/or fundamental rights acquires its specific relevance. Statements of rights are full of axiological connotations. After all, it is precisely their aspiration to universality that tends to foster the use of axiological semantic categories which are open to inclusion and decidedly vague at the same time. An important advantage to these broad categories is that they can be made to include connotative elements emerging from crossed narratives/contextualizations; in this way much of the morphological incompatibility related to cultural and normative differences can be overcome, so as to trigger the 'invention' of intercultural transaction platforms. In many cases, words or behaviors previously deemed to be morphologically incompatible may instead become parts of the same axiological/teleological

\footnotetext{
13 See Ricca, Culture interdette, $93 \mathrm{ff}$. and ibidem for extensive consideration of the differences between 'mute parts', intended as a semiotic background that circles around the content of the laws, and the notion of cd 'mute law', as developed by comparatists. Regarding 'mute law,' see Rodolfo Sacco, "Mute Law," American Journal of Comparative Law, 43 (1995): 455-67.
} 
category encapsulated in enunciations of human and/or fundamental rights. At that point, a kind of inter-contextual crossing-resonance will be produced between the different cultural and normative systems that will make it very difficult to deny legitimacy a priori and not allow conducts that are divergent in form but converging in sense and axiological relevance. Within such a process, the semantic contents of human and/or fundamental rights can work as interfaces of translation, or metaphorical grounds, thus 'horizontally' positioned with respect to the parts of intercultural and inter-normative encounters and their semiotic frameworks. They would function as semiotic-normative agencies ferrying reciprocal Otherness across their contexts of meaning, their chorologic-legal circuits. The traditional hierarchical-pyramidal positioning of rights statements would be relativized, by merging and including them within the translation process, so that they would act reflectively within each cultural-legal system only when intercultural translation is already underway. Moreover, this would avoid the hyper-relativistic and antagonistic-identitarian inflection of the semantic vagueness of statements of rights, the subsequent strategies of exclusion and conflict, so as to disclose new opportunities for dialogue and inclusion. The intercultural and 'horizontal' use of rights discourse might otherwise inspire acts of translation and transaction oriented toward the creation of conceptual and normative patterns positioned to organize an inter-European area of coexistence, communication and justice.

The overcoming of barriers and morphological rigidities means averting dangerous identitarian antagonisms. However, also in this case, what is at issue is not merely a reconnaissance survey. The creation of categories that are made inclusive by intercultural translation / transaction does not refer to functional equivalences already inherent in the different cultural codes and regulations. On the contrary, translating and transacting are always and in every case creative and thus intimately political activities. Their results are not knowable in advance, their success depends not on the state of affairs but on the sense of responsibility and chorologic awareness of the parties involved. The intercultural target will be within reach only for those who are able to see in the Other an unavoidable component of their own future. A component that must be taken into account when and if someone wants to figure out his existential space and its constitutive elements in order to manage them through coordinated and intelligent action. In every case, this attitude must be reciprocally embraced. Failing a flow of symmetrical efforts towards a reciprocal recognition, the aspirations to dominate, to exercise power over the Other, and the contrivance of devices aiming to neutralize his defenses, will inevitably prevail. The offspring of this will be the inability to produce 'spaces of prediction' as to the consequences of one's own actions, for these can be exclusively the result of bi- or multi-lateral trust and collaboration. As anyone knows, however, human history and its disasters are punctuated by the illusion of being able to neutralize the Other's subjectivity, due to a tendency to see this strategy as the most expeditious way to achieve one's own particular goals. That it is the shortest way but also the most shortsighted, however, history tries endlessly to teach us, even if we humans rarely prove to be good students.

The construction of a European intercultural space of harmonious intersubjective relationships represents a truly epic occasion, were we to be equal to our potential, an opportunity that unfortunately we Europeans risk losing. In my view, there is a tremendous amount of work to be done 'from below,' endeavoring to rewrite intercultural grammars for quotidian life and fulfilling the translation/transaction of legal paradigms through interdisciplinary commitment. Moreover, efforts to develop an Intercultural Europe could also be useful as a 
remedy to the resentments never placated and filed in the cultural consciousness of the people involved, at the dawn of modernity, in the construction of European nation-states. ${ }^{14}$. In many cases, the processes of national framing and homologation were imposed from above, by gestures of pure power totally disengaged from anthropological inclusion of and among different peoples. The state legal systems, in a completely specular way, overwhelmed anthropic landscapes teeming with cultural differences, silencing them under the stifling mantle of a 'legal equality grammar' riddled with meanings and axiological coordinates not shared by the diverse and manifold ethnic components of the rising 'nation'. The re-emergence of regional autonomy movements now at the forefront of Europe and more recently embodied by Scottish and Catalan referendums and/or plebiscites, are clear signs of the lack of anthropological knowledge that marked the political and legal experience of the making of the 'modern' Old Continent ${ }^{15}$.

The intercultural difficulties that have crippled attempts to elaborate common European legal disciplines in different areas (from contracts to succession) provide good reasons to rethink the modern state experience and address its deficiencies through the construction of an area of justice responsive to cultural differences. What is to be avoided, I argue, are: a) a repeated form of the top-down imposition of legal schemes that are socio-culturally alien to recipients; or, alternatively, b) institutional compromises that leave ongoing exigencies of cultural composition uncontrolled and uncontrollable and instead abandoned to the logic of a local autonomy completely broken away from the inescapable dynamics of transnational interdependence. In short, European institutions have to decide to resist the temptation of aligning their actions to a Euclidean pluralism presented in twoheaded, but only apparently opposite, manifestations. Both the politicalnomothetic strategies just cited are the result of misleading chorological visions, and a 'European Union' that would preach and practice them would only sow the

\footnotetext{
${ }_{14}$ In this regard, I would not be as certain as Shore is in regards to the processes of cultural nationalization coextensive with the birth and establishment of modern national states having overcome all their difficulties, and that the reactions produced by the overwhelming of anthropological dynamics extant in territories by centralized powers and engulfed in state frameworks are, so to speak, 'at peace.' See Cris Shore Building Europe: The Cultural Politics of European Integration (New York: Routledge, 2000), and specifically Id., "Whither European Citizenship? Eros and Civilization Revisited," European Journal of Social Theory 7(2) (2004): 40.

15 It is striking that regional resurgence is often accompanied by ethno-national radicalism, characteristically oriented against immigration but, strangely, grafted onto the claim of cultural, religious and legal traditions, allegedly shared across all of the EU, and in this respect distinct from those of the 'rest of the world.' The 'fortress of Europe' is the offspring of these contradictory imaginaries. A fortress that seems to be defended with even more force towards the outside as there are growing divisions haunting the inside. The contradiction, however, is only apparent. It depends on whether intra-European and extra-European or global dimensions of interculturality are two communicating vessels. Learning to manage intercultural relations with Otherness originating from the extra-European dimension provides excellent know-how to avoid falling into the trap of a proclaimed but inexistent infra-European cultural homogeneity. Conversely, a frequent practice of translation/transactions between European cultures would allow for an analysis of national cultures and their rights as circuits open to intercultural relations on a global scale. Moreover, the European chorology is interwoven with the global, which penetrates even into the most intimate plots of life conducted within nations and their cities. Accordingly, also within the circuit of intercultural Europe, people and institutions would miss the target if they were unable to envisage the intra-EU Other as a global actor. All of this without even having taken into account the presence of non-Western cultures and their representatives (thanks to contemporary migration flows) within the territory historically identified as Europe. On this issue, however, I refer to Ricca Oltre Babele; Id., Culture interdette; Mario Ricca., "Diritto Errante," Democrazia e sicurezza IV, 4, accessed January 18, 2015, http:/ / www.democraziaesicurezza.it, 1-101.
} 
seeds of its own self-dissolution.

In any case, the main symptom of the inefficiency of policies aprioristically imposed from above is the spread of corruption reported at both national and European levels, as well as within States-Community bureaucratic relationships ${ }^{16}$. Indeed, legal devices that do not speak the language of social ethics, understood and practiced by the people, the very subjects of law, are fatally destined to produce circuits of deviance and corruption. Conversely, the answer to the question "why do people obey the law" has an anthropological and culturalemotional aspect that is too often neglected. Experiences such as the Italian ${ }^{17}$ or the Yugoslav ${ }^{18}$ one, marked by relatively recent processes of national unification and administered without any effort to integrate ethnic-cultural differences, know diverse but equally dramatic repercussions. Mafias who lord over the territory and raging ethnic conflicts are both the sad offspring of operations of unification and juridification managed by a blind dirigisme, that fails to make the law and relevant institutions pay attention to anthropological lexicons inflected and acted upon in the daily life of the people.

And yet, even in the most attentive inquiries conducted by political scientists and lawyers, the anthropological deficit that haunts State or European legislative language remains without its own position in the taxonomy of the causes of corruption. In the same public opinion, the only 'legitimate' reason recognized as the determinant of the recent Scottish and Catalan oppositions remains exclusively the economic one. The only explanatory perspective provided by the media follows a kind of fixed script that narrates how the wealthiest and most powerful side, able to exploit certain resources, is eager to pull themselves free of those who depend on them and compete for the division of 'common' wealth. The cultural reasons seem to be regarded as purely specious. The invisibility of the "culture" component is, however, a paradox to be pondered and deserves some explanation. Could it be so because in the absence of any cultural competence none of us would be able to make such apparently culture-free judgments?

\section{Euclidean pluralism proved by positive law}

In order to complete the discourse developed so far in a legal-positive way, I propose the analysis of a normative statement of the EU that exemplifies, in a way I would deem almost spectacular, a concrete implementation of Euclidean

\footnotetext{
16 See Dirk Tänzler et al., eds., The Social Construction of Corruption in Europe (Aldershot: Ashgate, 2012).

${ }^{17}$ See Donatella della Porta and Alberto Vannucci, When Anti-Corruption Policy Fails: The Italian Case Eighteen Years After the mani pulite Investigations, in The Social Construction, ed. Tänzler et al., 133-61: who, however, does not specifically identify the legal-anthropological causes underlying the phenomenon of corruption in Italy. An exception, in the same essay collection, is represented by the article written by Luis de Sousa, 'Above the Law, Below Ethics': Some Findings on Portuguese Attitudes Towards Corruption, ibidem, 245-63, for the accuracy and depth of his psycho-anthropological analysis of Portuguese corruption. A discourse amenable to be extended to all the Southern European countries. From an anthropological point of view, but not concerned with the dichotomy between law and underlying customs, see Italo Pardo, Between Morality and Law: Corruption, Anthropology and Comparative Society (Aldershot: Ashgate, 2004); Id., "Who Is Corrupt? Anthropological Reflection on the Moral, the Criminal, and the Borderline," in Human Affairs, 23(2) (2013), 124-147; Dieter Haller and Cris Shore, eds. Corruption: Anthropological Perspectives (London-Ann Arbor (MI): Pluto Press 2005).

See also Karen Sykes, ed., Ethnographies of Moral Reasoning: Living Paradoxes of a Global Age (New York: Palgrave Macmillan, 2009).

${ }^{18}$ See Robert M. Hayden R.M., Blueprints for a House Divided: The Constitutional Logic of the Yugoslav Conflicts, (Michigan: The University of Michigan Press, 2000).
} 
pluralism. It comes to the "Regulation (EU) no. 650/2012 of the European Parliament and of the Council of 4 July 2012 on jurisdiction, applicable law, recognition and enforcement of decisions and acceptance and enforcement of authentic instruments in matters of succession and on the creation of a European certificate of succession." This text deals with a topic among the more 'sensitive,' culturally and anthropologically speaking, that is, the intergenerational transmission of wealth.

The normative document-it should be said-follows a previously failed attempt to produce common European legislation in matters of succession. This script has already been seen in other areas of legal experience. The Regulation is in some ways a makeshift solution. It combines a bit of a centralizing tendency with a bit of pluralism. Somehow, it is a consequence of the deficiency of intercultural dialogue in drafting European legislation, but it may also be due, in turn, to a lack of intercultural practice.

Due to space constraints, here I simply offer a reproduction of certain normative provisions, with a few added comments. This is in order to leave it to the reader to ascertain the traits of the Euclidean way of understanding pluralism within the legal discourse of the European Institutions.

I will start from point (6) of the "considered" premise of the normative text, going on to explain, then, the subsequent points:

(6) At its meeting in Brussels on 10 and 11 December 2009 the European Council adopted a new multi-annual programme called 'The Stockholm Programme - An open and secure Europe serving and protecting citizens'. In that programme the European Council considered that mutual recognition should be extended to fields that are not yet covered but are essential to everyday life, for example succession and wills, while taking into consideration Member States' legal systems, including public policy (ordre public), and national traditions in this area.

A characteristic Euclidean feature may be identified in this provision. The intentions and proclamations adhere to cultural and social aspects, while the implementations adhere only to technical-legal ones: legal systems, public order and national traditions, the latter included-please note- as a subclass of the category of "law."

(7) The proper functioning of the internal market should be facilitated by removing the obstacles to the free movement of persons who currently face difficulties in asserting their rights in the context of a succession having crossborder implications. In the European area of justice, citizens must be able to organise their succession in advance. The rights of heirs and legatees, of other persons close to the deceased and of creditors of the succession must be effectively guaranteed.

Here it is possible to track an index of misleading chorology inherent in Euclidean pluralism. It is recognizable in the quite presumptive reference to the European area of justice. An empty space, generated by the institutional power of the EU, hosts differences that are framed as being formalistically coordinated, regardless of any processes or procedures for intercultural translation/transaction. The utter absence of consideration of the anthropological dimension seems to betray a radically deficient vision of the cultural assumptions which necessarily underlie a European citizenship taken in its substance and, therefore, placed in the presumption of shared daily life habits.

(10) This Regulation should not apply to revenue matters or to administrative matters of a public-law nature. It should therefore be for national law to determine, for instance, how taxes and other liabilities of a public-law nature are 
calculated and paid, whether these be taxes payable by the deceased at the time of death or any type of succession-related tax to be paid by the estate or the beneficiaries. It should also be for national law to determine whether the release of succession property to beneficiaries under this Regulation or the recording of succession property in a register may be made subject to the payment of taxes.

I only observe that the criteria of exclusion or assimilation specified in this standard could produce, at the time of succession, cultural effects of enormous scope which are inevitably conflictual for relations between the subjects involved.

(12) Accordingly, this Regulation should not apply to questions relating to matrimonial property regimes, including marriage settlements as known in some legal systems to the extent that such settlements do not deal with succession matters, and property regimes of relationships deemed to have comparable effects to marriage. The authorities dealing with a given succession under this Regulation should nevertheless, depending on the situation, take into account the winding-up of the matrimonial property regime or similar property regime of the deceased when determining the estate of the deceased and the respective shares of the beneficiaries.

Here, we do not even need to consider the warning character of the provision. What matters, rather, is to observe how the centralization of the criteria for determining hereditary assets could create huge inequalities in cultural terms.

(15) This Regulation should allow for the creation or the transfer by succession of a right in immovable or movable property as provided for in the law applicable to the succession. It should, however, not affect the limited number ("numerus clausus') of rights in rem known in the national law of some Member States. A Member State should not be required to recognise a right in rem relating to property located in that Member State if the right in rem in question is not known in its law.

In this case, the possible inter-normative conflicts, therefore also intersubjective, are addressed through merely legalistic-positive instruments. The influence of culture on the institutes involved, as well as personal, ethical, and ideal expectations tailored according to cultural codes, seem invisible in the eyes of the European legislator.

(16) However, in order to allow the beneficiaries to enjoy in another Member State the rights which have been created or transferred to them by succession, this Regulation should provide for the adaptation of an unknown right in rem to the closest equivalent right in rem under the law of that other Member State. In the context of such an adaptation, account should be taken of the aims and the interests pursued by the specific right in rem and the effects attached to it. For the purposes of determining the closest equivalent national right in rem, the authorities or competent persons of the State whose law applied to the succession may be contacted for further information on the nature and the effects of the right. To that end, the existing networks in matters of judicial cooperation in civil and commercial matters could be used, as well as any other available means facilitating the understanding of foreign law.

This statement is symptomatic of the resistance of the drafters of European legal texts to the possibility of crossing the strictly normative boundaries of legal discourse when addressing matters of intercultural relevance. The instruments taken into account are private international law, comparative law and something surprisingly indeterminate: "any other available means facilitating the understanding of foreign law."

Is there no place-I wonder-within 'any other available means' for 
intercultural translation based on historical and anthropological inquiries?

Space constraints prevent me from continuing on with an analysis of the text that follows. I refer the reader to the text of the Regulation for "considered" nos. 23-25, which deal with the circumstances of life of the deceased; n. 29, which takes into account out of court resolution of disputes regarding succession, also in accordance with the laws of states different to the member state, and so raising issues of intercultural intra-European and extra-European or global relevance; n. 34, which talks about the 'harmonious functioning of justice' without any referral to the cultural dimension of the people involved, but only with regard to profiles and procedural solutions; n. 38, which confronts the necessity to ascertain whether the choice of law to be applied by the testator is not directed to frustrate the expectations of those entitled to legitimate shares, all specifications once again lacking any reference to any kind of anthropologically-oriented evaluation; n. 58, where it is possible find a hint of culture via Article 21 of the EU Charter of Fundamental Rights. However, the principle of non-discrimination is likely to receive a pyramidal application, not drawing on a methodology suited to support a horizontal implementation engaged in a process of intercultural translation; n. 71, which indirectly conjures up the problem of 'good faith'; the legal aspects-explicit and implicit ones (the 'mute parts' of legal discourse)-of the information contained in the European Certificate of Succession seem to be ignored, when they could instead be evaluated through an anthropological-intercultural assessment; n. 81, where Euclidean pluralism finds explicit expression in the reference to the rules of respect and implementation of the Fundamental Rights of the European Union. The Regulation complies with them in textual and centralized terms. The courts will have to respect them by application, taking into account the right to selfdetermination of the member states and their people: "how," using what methodology, however, is not specified.

Turning to the legislation itself, Articles 4, 22 and 5 are relevant; they determine the two main criteria for the identification of the applicable law and the competent court in order to settle the succession of people who have resided in two or more European countries during the course of their lives. These criteria are (1) the place of habitual residence at the time of death and (2) the choice of law. In this regard, it is questionable whether the principles of habitual residence and of the choice of law, provided that the chosen law coincides with the deceased's country of citizenship, would respect the cultural identity of the deceased and the heirs, or instead reflect those interests tied to national sovereignty and its claims for economic-territorial control. A similar consideration is also extensible to art. 10.2 regarding the subsidiary jurisdiction gauged according to the place where the assets of the estate are located, and art. 12.2, both of which tend to assemble centralist policies and localistic exceptions, alternatively legitimized on the basis of procedural devices.

Articles 20, 21 and 22, establish the general criteria for determining the law applicable to succession. Habitual residence and choice of the testator, as mentioned, are the primary considerations. The second declines the scope of the subject-area correlation in a liberal fashion, implicitly embodied in the criterion of residence. A very interesting reference is found in Article 21.2, which provides:

Where, by way of exception, it is clear from all the circumstances of the case that, at the time of death, the deceased was manifestly more closely connected with a State other than the State whose law would be applicable under paragraph 1, the law applicable to the succession shall be the law of that other State.

The meaning and methods to be used for determining the "manifestly more 
closely connected with a State other than the deceased" remain conspicuously unresolved.

Another significant expression of Euclidean pluralism, and its dual facet is Article 25. It disciplines the agreements as to succession and the criteria for stating their regime in the case of potential competition of laws. The interesting aspect is that this criterion does not apply if one of the parties of the agreement is subject to the law of a state that does not provide for such kind of agreements. Similar considerations can be advanced for the art. 30. Article 31, concerning the adaptation between the figures of rights in rem, reflects the 'considered' Article 16, analyzed above.

Another rule relevant to interculture is Article 37, entitled "States with more than one legal system-inter-personal conflicts of laws." Needless to say, even here the analysis criteria are only formalistic, without any reference to cultural and/or religious profiles to be evaluated on the basis of anthropological assessments.

A provision distinctly characterized by Euclidean pluralism is Article 62, which introduces the European Certificate of Succession. This article states that the use of the Certificate is not mandatory and does not replace other documents used for similar purposes in the individual states. Once applied for and issued, however, the Certificate will be valid in all member states and produces the effects listed in Article 69 in the Member State whose authorities issued it in accordance with the Chapter VI of the Regulation. Overarched by the personal autonomy and the recognition of the testator's free choice to request the certificate, once again the alternative between transnational homologation and national particularism takes precedence, a dialectic or exclusive alternative that risks tearing apart the family life of those who will manage the legacy straddling different legal and cultural systems.

I close my discourse pointing out that under Article. 83, the Regulation will apply to the succession of deceased persons on or after August 17, 2015. I wonder if there might still be time to understand the intercultural deficits of this legislation taken both as a whole and in its sources of nomothetic inspiration. I raise this issue stressing that the use of chorological-intercultural law, and that of human and/or fundamental rights in particular, can serve to normatively redefine spaces of existence for subjects. If the spaces of experience alter the scope and meaning of both the cultural knowledge and legal standards, then working on the words of the law through processes of intercultural re-categorization is equivalent to becoming able to remodel the cartographies of individual and collective experience. The expression "area of justice," launched by the European legislators, is essentially bidirectional. It appears as justice unfolds in a spatial frame and, simultaneously, as the space of experience is produced from the exercise of justice. Put diversely, this means that space and culture, word and space, space and law, indeed all spatial categories and linguistic categories or regulations are false dichotomies. Both wings of every divide embody entities or magnitudes that are mutually continuous and coextensive. In the end, the effort to understand the chorological interweaving between rights, spaces and paths of inter-subjectivity is the condition for the future sociopolitical geometries of the European Union, at least in the field of human relations, if they are to have any hope of infringing upon Euclid's fifth theorem to move towards the realization of an anthropologically inclusive pluralism. Europe has been made (perhaps); will we succeed in making Europeans? 